\title{
Traços Aspectuais do Pretérito ImPerfeito do Indicativo E do Passado Progressivo no PoRTUGUÊS EM CONTEXTOS DE VARIAÇÃo
}

\author{
Aspectual features of Portuguese pretérito \\ imperfeito do indicativo and passado progressivo \\ in context of variation
}

Raquel Meister K. Freitag*

\section{INTRODUÇÃo}

Aparentemente, o português brasileiro apresenta duas formas verbais para codificar o mesmo valor temporal-aspectual, o pretérito imperfeito (IMP) e o passado progressivo (PPROG), como as destacadas em (1) e (2):

(1) Na época que eu mais precisei dele, que eu mais precisava (IMP) de um apoio, foi quando a minha mãe morreu. (SC FLP 03)

(2) Aí também foi na época que a gente voltou, a gente estava precisando economizar pra começar nossa vida. (SC FLP 01)

IMP é a forma gramaticalizada na língua (no sentido de pertencer à gramática) e apresenta expressão regular no paradigma verbal. Já a construção de passado progressivo é uma forma em processo de gramaticalização (MENDES, 1999; WACHOWICZ, 2003). Neste trabalho, 
Freitag, R. M. K. Traços Aspectuais do Pretérito Imperfeito do IndicAtivo E...

pretende-se discutir:

i) Quais os traços semânticos que caracterizam o valor temporal-aspectual expresso pelas formas IMP e PPROG em (1) e (2); e

ii) Se as formas IMP e PPROG podem ser consideradas como equivalentes semânticos na expressão desse valor temporalaspectual no português.

Os pressupostos para a análise são dados pelo estudo de Molendijk (2005), sobre os usos do past progressive no inglês (equivalente a PPROG no português) e o imparfait francês (equivalente ao IMP no português), e também pelos estudos de Castilho (2003) e Wachowicz (2003). Assim como no estudo de Molendijk (2005), as formas no português também apresentam diferenças, mas em alguns contextos temporais-aspectuais, podem ser consideradas como equivalentes semânticos. Os estudos de Castilho (2003) e de Wachowicz (2003) sugerem que IMP e PPRPG estão ocorrendo com a mesma função semântica no português.

A estrutura do texto é a seguinte. Primeiramente, a categoria aspecto é apresentada, com a discussão focada para a questão do imperfectivo, com uma proposta de classificação aspectual que englobe a dimensão quantitativa e qualitativa do aspecto (Wachowicz, 2003; Castilho, 2003) e o papel do traço lexical na composição da leitura aspectual. Em um segundo momento, a dimensão temporal é incorporada à análise, resultando no conjunto de traços temporais-aspectuais que descrevem as situações de (1) e (2), o qual é denominado de situação passada em curso.

\section{A CATEgoria Aspecto}

Existem diferentes perspectivas de estudo da categoria aspecto, sem que haja um consenso sobre a melhor ou mais correta abordagem. A perspectiva que adoto é apenas mais uma, a que neste momento, considero a mais adequada para lidar com o fenômeno em estudo. Por isso, parto da definição clássica de que enquanto a categoria gramatical tempo é responsável pela constituição temporal externa, a categoria gramatical aspecto costuma designar os diferentes modos de perceber a constituição temporal interna de uma situação (COMRIE, 1976).

Quanto à expressão, o aspecto não é marcado exclusivamente por um elemento gramatical. Existem diferentes tipos de manifestação do aspecto. Há o aspecto inerente ao verbo; há o aspecto codificado pela morfologia verbal e, ainda, o aspecto codificado pelos modificadores adverbiais, todos interagindo entre si e resultando no aspecto da situação. Uma consideração 
a ser feita é que não há consenso também da existência de aspecto como uma categoria em todas as línguas. As línguas eslavas têm uma categoria aspectual, já que possuem oposição binária aspecto marcado/não-marcado. Já o alemão e as línguas românicas não teriam a categoria aspecto porque não há oposição binária no paradigma verbal (EMMEL, 2005). Ilari (1997, p. 38), entretanto, reconhece no português uma categoria aspectual, relacionada à expressão da duração, que se manifesta na oposição pretérito perfeito/pretérito imperfeito.

A oposição aspectual básica é que uma situação pode ter sua constituição interna considerada ou não pelo falante. No primeiro caso, imperfectivo, (aspecto marcado), e no segundo caso, perfectivo (nãomarcado) ${ }^{1} . O$ aspecto perfectivo é caracterizado pela perspectiva global da situação, que é expressa fechada, formando uma unidade ou conjunto, do qual não interessa referir à sua constituição interna. Já o aspecto imperfectivo expressa diferentes nuanças da temporalidade interna: que se desenrola (cursivo), ou selecionando fases do tempo interno (inicial, medial, final), ou expressando estados resultativos, entre outras possibilidades. Ou seja, o imperfectivo não identifica os pontos inicial ou final da situação, focalizando o seu desenvolvimento, em contraponto ao perfectivo, que enfatiza os pontos inicial ou final. E a escolha por uma marcação aspectual depende do relevo dado pelo falante. A imperfectividade pode ser caracterizada como a propriedade de atribuir extensão às situações. A extensão das situações pode ter nuanças com relação ao intervalo temporal e com a quantidade de vezes que ocorrem, como ilustram as situações destacadas em (3)-(5).

(3) Era dez da noite, a mãe fazia a janta, quando a gente recebeu a notícia que ele se acidentou. (SC FLP 23)

(4) E era Figueirense fanático e do Flamengo. Quando o Flamengo perdia, ele quebrava o rádio. (SC FLP 19)

(5) Antigamente, o ônibus que passa por aqui, o caminho pra ir para os Ingleses é um caminho que vem, era mais pra dentro assim, né? é antes do asfalto. Isso é depois que abriu aquele asfalto ali, porque, né? E é, e era morro. Mas aí depois começaram, né? fizeram aquele asfalto tudo ali tiraram o morro completo ali. Mas era um morro assim bem alto mesmo que no dia de chuva o ônibus quebrava, né? que era muita lama, que ainda não era calçado. Então a gente perdia tempo à beça esperando que viesse outro ônibus. O ônibus quebrava toda hora, toda hora. Mas era a maior dificuldade, sabe? pra gente se locomover de ônibus. (SC FLP 18)

Marcação, especificamente no que se refere a aspecto, e seus critérios são retomados no capítulo da metodologia. 
Freitag, R. M. K. Traços Aspectuais do Pretérito Imperfeito do IndicAtivo E...

Em todos os casos, a escolha do morfema verbal, associada aos modificadores temporais, enfatiza a extensão da situação. Mas, em (3), a situação de fazer a janta aconteceu uma única vez, em um momento específico, dez da noite. Em (4), a situação de quebrar o rádio aconteceu possivelmente mais de uma vez, em um momento específico, quando $o$ Flamengo perdia. E em (5), a situação de quebrar o ônibus ocorreu, com certeza, mais de uma vez, em um intervalo temporal que não é determinado. Não é a forma de IMP, traço comum a todas as situações destacadas, a única responsável pela expressão dessas nuanças aspectuais, mas sim a sua interação com outros elementos contextuais, explícitos ou implícitos, que levam a uma leitura aspectual. Para dar conta destas nuanças aspectuais, na seção a seguir, discuto uma proposta de classificação que considera as diferentes formas de expressão de aspecto e a sua interação, numa perspectiva composicional.

\section{CLASSIFICAÇÃo ASPECTUAL}

Dentre as diversidades tipológica e terminológica de classificação aspectual do imperfectivo, a que mais se mostra apropriada para o estudo do IMP e do PPROG é a proposta de Wachowicz (2003). Com base em Castilho (2003) e Verkuyl (1993), a classificação aspectual de Wachowicz (2003) pode ser considerada composicional, uma vez que o aspecto de uma situação é o resultado final decorrente da interação entre o aspecto inerente do verbo, $o$ objeto do verbo, o sujeito, o tipo de complemento adverbial e, por fim, o contexto. A classificação de Wachowicz foi proposta para as formas de progressivo do português constituídas por estar + Vndo. Fundamentada nas constatações de Godoi (1992), ela afirma que a forma do PPROG e a do IMP estão co-ocorrendo com a mesma função semântica no português (Wachowicz, 2003, p. 214), logo, a sua proposta de classificação aspectual também deve dar conta dos dados de IMP. Wachowicz toma como ponto de partida a classificação de Castilho (2003) e propõe a classificação do Quadro 1.

QUADRO 1: ClASSIFICAÇÃO ASPECTUAL (WACHOWICZ, 2003, P. 5)

\begin{tabular}{|c|c|c|c|c|}
\hline \multicolumn{5}{|c|}{ Valores aspectuais/exemplos } \\
\hline \multirow{7}{*}{$\begin{array}{c}\text { Estados de } \\
\text { coisas }\end{array}$} & Permansivo & & A árvore es & endo \\
\hline & \multirow{5}{*}{ Operativo } & \multirow{3}{*}{ Critério quantitativo } & Episódico & João está plantando uma árvore \\
\hline & & & Iterativo & João está plantando três árvores \\
\hline & & & Habitual & João está plantando árvores \\
\hline & & \multirow{2}{*}{ Critério qualitativo } & Perfectivo & João plantou uma árvore \\
\hline & & & Imperfectivo & João está plantando uma árvore \\
\hline & Resultativo & \multicolumn{3}{|c|}{ João pôs-se a plantar árvores } \\
\hline
\end{tabular}


De acordo com Wachowicz (2003), no Quadro 1, os valores aspectuais estão pautados em três estados de coisas: permansivo, operativo e resultativo: o estado permansivo não muda no tempo, sendo incontável; o operativo é um estado de coisas que muda no tempo, podendo ser contado; e o resultativo é um estado de coisas que foca o resultado da ação, e não nela própria.

O estado de coisas permansivo é homogêneo e contínuo dentro da estrutura temporal, é um estado de coisas que "permanece" no tempo. O estado de coisas operativo é subcategorizado em dois critérios: o da qualidade (imperfectivo e perfectivo) e o da quantidade (episódico, habitual e iterativo). Estes critérios não são excludentes, pois João plantou uma árvore pode ter leitura episódica e perfectiva.

O subcritério qualitativo do estado operativo pode ser visto como a relação entre a situação e os pontos extremos da estrutura temporal. 0 perfectivo é o aspecto que tem os pontos extremos da estrutura temporal envolvidos na leitura aspectual; já o imperfectivo, não, ou seja, não se interpretam os pontos inicial e final da estrutura temporal. Porém, o fato de os pontos extremos da estrutura temporal não serem considerados não significa que o imperfectivo não tenha determinação. Assumindo a perspectiva de Godoi (1992), a linguagem formal da teoria dos conjuntos permite melhor compreender a relação entre a situação e o intervalo da estrutura temporal - referência - que culminam na interpretação imperfectiva ${ }^{2}$.

Para que um conjunto, ou intervalo de estrutura temporal, não tenha seus pontos extremos interpretados é preciso estar contido totalmente em outro, que tem os pontos extremos interpretados. Ou seja, um intervalo de tempo deve estar totalmente contido em outro. Se denominarmos ao primeiro intervalo de tempo de situação (S) e ao segundo de referência $(\mathrm{R})$, podemos operar com os conceitos de Reichenbach (1947), assim como na categoria de tempo, de acordo com as propostas de Johnson (1981) e de Godoi (1992). Segundo Godoi, se existe um tempo de referência e um tempo da situação, a relação entre eles determina a leitura aspectual. Assim, o perfectivo é uma relação de inclusão própria do tempo da situação no tempo da referência, cuja formulação é $S \mathrm{~d} R$, em que a situação, contraposta à referência, tem as extremidades, é fechada. Já o imperfectivo é uma relação

2 Não se trata de uma discussão formal acerca do aspecto imperfectivo. Os pressupostos da semântica formal são utilizados para compor a relação estabelecida entre situação e referência que determina a leitura aspectual qualitativa (GODOI, 1992; JOHNSON, 1981; LONGO; CAMPOS, 2003; WACHOWICZ, 2003; 2005). 
de inclusão própria do tempo de referência no tempo da situação, cuja formulação é R d S, em que a situação, contraposta à referência, não tem as extremidades, é aberta ${ }^{3}$. As relações entre situação e referência estão esquematizadas na Figura 1.

FIGURA 1: ESQUEMA BÁSICO DAS RELAÇÕES ASPECTUAIS NA PERSPECTIVA QUALITATIVA (ADAPTADO DE GODOI, 1992)

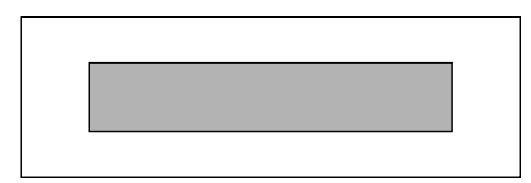

imperfectivo

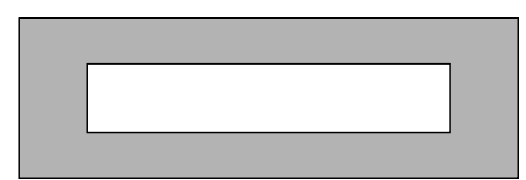

perfectivo

ـ Intervalo da situação

Intervalo da referência

O IMP e o PPROG são formas relacionadas à expressão de aspecto imperfectivo. Castilho (2003, p. 95-96) aponta as seguintes características do imperfectivo: (i) apresenta uma predicação dinâmica de sujeito/específico; (ii) que compreende fases: fase inicial (imperfectivo inceptivo), fase em pleno curso (imperfectivo cursivo), ou uma fase final do estado de coisas (imperfectivo resultativo).

Quando IMP e PPROG codificam situação passada em curso, fica mais nítida a noção de imperfectivo cursivo ${ }^{4}$. Retomando (3), a situação passada em curso é a mãe fazia a janta, e há duas informações textuais que determinam a referência temporal: era dez da noite e quando a gente recebeu a notícia que ele se acidentou. A situação e a referência de (3) podem ser esquematizadas como na Figura 2.

\section{FIGURA 2: ESQUEMA DA RELAÇÃO SITUAÇÃO-REFERÊNCIA DE (3)}

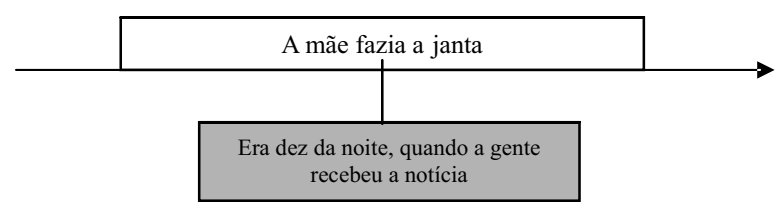

De acordo com Molendijk (2005), $\mathrm{R}$ d S se $\mathrm{R}$ corresponde a um instante; $\mathrm{R}$ fS se $\mathrm{R}$ corresponde a um intervalo.

4 A correlação IMP e imperfectivo, no entanto, nem sempre é verdadeira. Os usos de IMP narrativo, por exemplo, nem sempre se referem a situações imperfectivas (FLEISCHMAN, 1995). 
O esquema da relação entre a situação e a referência de (3) deve ser entendido da seguinte maneira: (i) o eixo de orientação temporal é a seta horizontal; (ii) a situação é apresentada como em andamento, estendida (o retângulo branco); e (iii) a referência é apresentada de modo pontual (o traço perpendicular ao eixo de orientação temporal, que marca o ponto de intersecção entre a situação e a referência). A situação de fazer a janta tem, obviamente, um início e um fim. Porém, contraposta à referência, a situação é vista como em andamento, sem comprometimento com a indicação de início ou fim. É preciso ficar claro, neste momento, que a noção de situação em andamento não é marcada exclusivamente pela forma verbal, o IMP mais especificamente. A noção de aspecto adotada é composicional, portanto, fatores de outra natureza interagem na determinação do aspecto de uma situação. Neste caso específico, o aspecto lexical, ou aspecto inerente do verbo, tem papel fundamental, tema que é retomado mais adiante. Retomando, o subcritério qualitativo do aspecto é determinado pela relação entre a situação e a referência. Enquanto na categoria tempo, a relação é de ordenação - e IMP e PPROG caracterizam-se pela sobreposição entre situação e referência -, na categoria aspecto a relação é de inclusão - e IMP e PPROG são caracterizados pela inclusão própria do tempo de referência no tempo da situação.

O subcritério quantitativo do estado de coisas operativo refere-se à quantidade de vezes que uma situação ocorre no intervalo da estrutura temporal. A ocorrência de uma situação uma única vez no intervalo da estrutura temporal caracteriza a leitura episódica. Já a ocorrência de uma situação mais de uma vez dentro da estrutura temporal pode ser iterativa, se a estrutura temporal for determinada, ou habitual, se a estrutura temporal for indeterminada, como esquematizado no Quadro 2.

QUADRO 2: ESQUEMA BÁSICO DAS RELAÇÕES ASPECTUAIS NA PERSPECTIVA QUANTITATIVA

\begin{tabular}{ccc} 
& \multicolumn{2}{c}{ Intervalo da estrutura temporal } \\
\cline { 2 - 3 } Recorrência da situação & Determinado & Indeterminado \\
\hline Uma vez & Episódica & \\
\hline Mais de uma vez & Iterativa & Habitual \\
\hline
\end{tabular}

Castilho (2003) chama de semelfactivo e iterativo os aspectos operativos qualitativos; a distinção entre iterativo e habitual é feita por Wachowicz (2003), embora o autor faça distinção entre iterativo determinado e indeterminado.

Quanto ao critério qualitativo, Castilho (2003), subespecifica o imperfectivo em inceptivo (duração em que se destacam os momentos iniciais), cursivo (situação em pleno curso, sem referência às fases final ou 
inicial) e terminativo (assinala os momentos finais da duração). Como na perspectiva qualitativa o imperfectivo é caracterizado pela relação de inclusão própria da referência no intervalo da situação, parece incompatível pensar em recorrência da situação (perspectiva qualitativa) em situações imperfectivas cursivas. Ou seja, se uma situação é imperfectiva cursiva, só pode ocorrer uma única vez, logo, tem que ser episódica.

Retomando, de acordo com esta proposta de classificação, nos casos (3) a (5) da seção anterior, em (3), a situação de fazer a janta tem leitura episódica, pois o intervalo da estrutura temporal é determinado e a situação ocorreu uma única vez. Em (5), a leitura aspectual da situação de quebrar o ônibus é habitual, pois ocorre mais de uma vez, em um intervalo de tempo indeterminado. Já a situação de (4) é aspectualmente ambígua. Pode-se imaginar um contexto tal que o Flamengo perca recorrentemente durante o Campeonato Brasileiro de 2005 e o sujeito quebrasse o rádio na mesma freqüência, teríamos aspecto imperfectivo iterativo. Mas, em um contexto tal que se a crise do Flamengo fosse permanente (ou seja, o Flamengo é um time ruim mesmo), o aspecto da situação poderia ser considerado imperfectivo habitual.

A proposta de Wachowicz (2003) é a adotada para a análise de IMP e PPROG, mais especificamente, quando as formas podem ser consideradas como tendo o mesmo valor de verdade, funcionando como variantes de uma mesma variável lingüística, no contexto em que codificam situação passada em curso. Ora, uma situação em curso no passado pode ser recoberta por todas as nuanças quantitativas do imperfectivo, o que inviabilizaria uma análise variacionista, por conta da quantidade de fatores que atuam no modelo. Por isso, proponho uma "limpeza" na categoria do aspecto, para delimitar o campo de significação em que IMP e PPROG podem se comportar como variantes. Para justificar a "limpeza", gostaria de relembrar que não existe uniformidade na literatura para a rotulação dos valores aspectuais, menos ainda consenso.

Com base no conceito de número verbal proposto por Coseriu (1980 apud BORBA COSTA, 1997), que se refere à repetição ou não do fato verbal (oposição iterativo vs. semelfactivo), Costa (1997) exclui o iterativo da categoria de aspecto, pois "a repetição de um fato não pode, a rigor, ser interpretada como pertinente à sua constituição interna". Borba Costa (1997, p. 25) explica que

no caso da iteração, há fatos verbais idênticos que se repetem no tempo. São, portanto, fatos que se sucedem na linha do tempo, não se fazendo necessariamente referência à constituição temporal interna de cada um deles. Temos aí, portanto, o caso de fatos distribuídos no tempo, e não de tempo interno ao fato. 
A autora também discute se é pertinente considerar a habitualidade no plano do aspecto. Um fato verbal pode tornar-se habitual por continuidade ou por iteratividade. Por continuidade, é conseqüência de um fato de número singular ser tratado como durativo. Por iteração, é conseqüência de um fato de número plural, vários fatos verbais que se estendem no tempo, e aí não é aspecto, pois extrapola a constituição interna da situação. Observem-se (6) e (7):

(6) Ele sai de casa às 8 h há três anos.

(7) Ele cria gatos há três anos.

Em (6), a situação de sair de casa é habitual por iteração, pois se refere a sucessivas saídas às $8 \mathrm{~h}$ pelo intervalo de três anos. A situação verbal pode ser fracionada em unidades menores (cada saída). Já (7) criar gatos é uma situação habitual por continuidade, pois se refere a um intervalo contínuo. Não se pode fracionar a situação em unidades menores de criação. Assim, de acordo com Borba Costa, a iteratividade não está no escopo do aspecto, assim como a iminencialidade ${ }^{5}$. Para que o iterativo e o habitual por iteratividade sejam considerados "aspecto", ou seja, se referiram à constituição temporal interna, é preciso que eles façam parte de um fato maior, na forma de fases desse fato $^{6}$. 0 estatuto (in)aspectual da habitualidade e da iteratividade não será discutido. Com base nas restrições de Borba Costa, o único valor aspectual relevante para esta análise do IMP e PPROG é o episódico - ou semelfactivo, na terminologia de Castilho (2003). Com esta restrição, o número de casos de análise se reduz drasticamente. Uma análise preliminar, intuitiva e não sistematizada nas entrevistas sociolingüísticas do Banco de Dados do Projeto VARSUL aponta que os usos de IMP habitual e iterativo são os mais freqüentes, embora a intercambialidade com PPROG nem sempre seja possível, tanto em termos de freqüência, como em termos de possibilidade.

Porém, quando se trata de uma situação episódica em curso, as duas formas podem ser encontradas em uso. Antes de discutir o valor aspectual de situação episódica em curso, é necessário explorar a questão do aspecto inerente ao verbo, ou aspecto lexical, que tem participação significativa na composição da leitura aspectual, especialmente na situação episódica em curso (BONOMI, 1998).

5 O valor iminencial não pode ser considerado aspecto, pois não se refere à estrutura temporal interna do fato, mas sim ao momento anterior: "Ouando eles iam casar, ele morreu" (BORBA COSTA, 1997, p. 26).

6 Diversas situações podem ser tomadas em conjunto caracterizando um processo em que cada uma delas pode ser considerada como uma parcela da constituição temporal interna de uma outra situação mais ampla. Neste caso, o escopo do aspecto extrapola o limite da frase e adentra no discurso. (BORBA COSTA, 1997, p. 28). 
FreitAG, R. M. K. Traços Aspectuais do Pretérito Imperfeito do IndicAtivo E...

\section{AsPecto LEXICAL}

$\mathrm{O}$ aspecto inerente ao verbo, ou acionalidade, ou aktionsart, ou aspecto lexical, refere-se não à estrutura temporal interna da situação, mas ao tipo de situação propriamente ${ }^{7}$. De acordo com Vendler (1967), as situações subdividem-se em quatro classes aspectuais, de acordo com seu desenvolvimento, tempo verbal e as suas relações com os modificadores temporais. As quatro classes aspectuais são estado (situação não-dinâmica, como ser feliz ou acreditar), atividade (situação cujo ponto final é aberto, como correr, empurrar um carrinho), achievement (situação momentânea, como alcançar o topo da montanha, vencer a corrida) e accomplishment (situação com ponto final definido, como desenhar um círculo, correr 1 $\mathrm{km}$ ). Se alguém corre ou empurra um carrinho, no próximo momento continua correndo ou empurrado um carrinho. Mas se alguém corre $1 \mathrm{~km}$ ou desenha um círculo, no próximo momento não continua desenhando um círculo ou correndo $1 \mathrm{~km}$. Se alguém parar enquanto corre $1 \mathrm{~km}$ ou desenha um círculo, não terá corrido $1 \mathrm{~km}$ nem desenhado um círculo. Mas se alguém que corre ou empurra um carrinho parar, de fato, correu ou empurrou um carrinho. Empurrar um carrinho não tem um período de tempo especificado para acabar, já desenhar um círculo necessariamente tem um ponto final. A diferença entre correr e correr $1 \mathrm{~km}$ é que correr, assim como empurrar, é uma atividade; já correr $1 \mathrm{~km}$, assim como desenhar um círculo, é um accomplishment.

Situações como estar feliz ou acreditar não indicam processo andando no tempo, mas podem ser dadas como verdadeiras ou falsas durante um período de tempo. Algumas podem predicar por um período pontual, outros por um período maior ou menor de tempo. Vencer uma corrida ou reconhecer um amigo, por exemplo, são situações com momento definido, pontual. Já acreditar em duendes ou amar a natureza são situações que ocorrem durante um espaço de tempo. As situações apresentam esquemas temporais distintos: no primeiro caso, trata-se de um achievement; no segundo caso, estado. Note-se que, mesmo sem tratar explicitamente do assunto, a classificação de vendler considera o complemento verbal para compor a interpretação aspectual. A noção composicional de aspecto é retomada por Verkuyl (1993), que formaliza a aplicação da classificação aspectual ao sintagma verbal, e não necessariamente ao item lexical do verbo.

Há discussões na literatura acerca das semelhanças e diferenças entre aspecto inerente ao verbo, acionalidade, aktionsart e aspecto lexical; não me comprometo com as definições. 
Rothstein (2004, p. 12) interpreta as classes aspectuais de Vendler com base em duas propriedades: i) se a situação denotada por um predicado qualquer tem um ponto final natural, ou seja, se possui um thélos, um ponto de culminação; e ii) se a situação pode ser analisada quanto ao seu progresso no tempo, ou seja, se pode ser dividida em fases, conforme $o$ Quadro 3.

QUADRO 3: PROPRIEDADES DAS ClASSES ASPECTUAIS (ROTHSTEIN, 2004, P. 12)

\begin{tabular}{lcc}
\hline & {$[+/-$ fases $]$} & {$[+/$ - télico $]$} \\
\hline Estado & - & - \\
Atividade & + & - \\
Achievement & - & + \\
Accomplishment & + & + \\
\hline
\end{tabular}

Observe-se que estados e achievements são classes aspectuais que, de acordo com esta proposta, não podem ocorrer com IMP ou PPROG quando codificam situação episódica passada em curso. Porém, considerando a composicionalidade, a interação entre aspecto lexical, aspecto gramatical, adjuntos e, por fim, o contexto, permitem realizações como (8), em que duas situações pertencentes à classe dos estados codificam uma situação passada em curso.

(8) A gente, criança e estava imaginando, achava que ele estava lá.

A telicidade, um traço inerente ao verbo, no plano lexical, parece estabelecer relações com a perfectividade/imperfectividade, um traço qualitativo do aspecto gramatical. Embora as noções de aspecto gramatical e lexical sejam independentes, parece haver uma convergência entre aspecto imperfectivo e verbos atélicos, e aspecto perfectivo e verbos télicos. Os verbos télicos expressam ações que tendem a um ponto culminante para que a situação realmente ocorra, como matar, morrer, cair, engolir, etc. Verbos atélicos expressam uma ação em sua duração, independente de um ponto culminante para que se considere a existência da situação, como mastigar, viver, escrever, acompanhar. Assim, pode-se estabelecer uma correlação entre os verbos télicos, que atualizam aspecto perfectivo, e os verbos atélicos, que atualizam aspecto imperfectivo, apesar de flexão, adjuntos e complementos interagirem e provocarem mudança de uma categoria a outra. Por conta da possibilidade de correlação entre telicidade ò perfectividade, e atelicidade ò imperfectividade, os aspectos lexical e gramatical aparentemente são redundantes. Bertinetto (2001, p. 178) apresenta uma proposta que pretende desfazer a aparente redundância da codificação aspectual, 
Freitag, R. M. K. Traços Aspectuais do Pretérito Imperfeito do IndicAtivo E...

estabelecendo os domínios aspectuais de cada uma das categoriais. Ele retoma a classificação vendleriana e a caracteriza, não por duas, mas por três propriedades inter-relaciondadas: duratividade, dinamicidade $e$ homogeneidade .

QUADRO 4: PROPRIEDADES DAS CLASSES ASPECTUAIS (BERTINETTO, 2001)

\begin{tabular}{lccc}
\hline & Durativo & Dinâmico & Homogêneo \\
\hline Estados & + & - & + \\
Atividades & + & + & + \\
Achievements & - & + & - \\
Accomplishments & + & + & - \\
\hline
\end{tabular}

A propriedade da homogeneidade refere-se à ausência de um limite interno inerente em uma dada situação, sendo fundamental para a distinção entre telicidade e atelicidade. Situações atélicas - estados e atividades - são definidas como: se uma situação $s$ ocorre num intervalo de tempo $I$, então $s$ também ocorre em cada subintervalo de $I$. Ou seja, uma situação homogênea é aquela que não muda de natureza. Em contraponto, accomplishments e achievements não são homogêneos porque são télicos.

A dinamicidade é uma propriedade caracterizada a partir da observação dos estados. Situações de estado são "densas", não apresentam nenhum desenvolvimento interno e recebem o traço [-dinâmicas], o que, em tese, justifica o barramento do emprego do progressivo (no caso específico, de situações episódicas passadas em curso). Achievements, accomplishments e atividades são situações [+ dinâmicas].

Bertinetto (2001) propõe que a seqüência mínima de gestos que instancia uma dada situação dinâmica seja denominada de átomo dinâmico, e os estados, compostos por átomos estáticos. Átomos dinâmicos correspondem à granularidade mínima definida pela situação, e por isso, não são divisíveis indefinidamente. Os átomos estáticos podem ser subdivididos indefinidamente, já que os estados não apresentam granularidade. Esta diferenciação subsidia a hipótese de que as situações

8 De acordo com Bertinetto (2001), as classes acionais são aplicadas a um predicado considerando que o predicado deve ser visto em sua estrutura argumental. Enquanto desenhar é sempre uma atividade, desenhar um círculo é um accomplishment; a natureza dos determinantes também é relevante, já que desenhar [um, três, os círculos] é um accomplisment, mas desenhar círculos é novamente uma atividade. Do mesmo modo, João caiu é um achievement, enquanto que as frutas caíram ao longo da estrada [durante toda a viagem] é uma atividade. Assim, um dado predicado pode ser relacionado a mais de uma classe acional, dependendo da sua composição. Vale frisar que esta proposta de classificação de aspecto lexical é compatível com a proposta de classificação de aspecto gramatical adotada. 
podem ser vistas como sendo compostas por conjuntos de átomos dinâmicos e/ou estáticos.

A propriedade da duratividade é responsável pela diferenciação entre situações [- durativas], como os achievements, constituídos por um único átomo dinâmico seguido de um átomo estático que instancia o ponto de culminação atingido pela realização da situação, de situações [+ durativas] como os accomplishments, que envolvem um conjunto de átomos dinâmicos seguidos de um átomo estático. Os accomplishments diferenciamse das atividades - também [+ durativas] e constituídas por um conjunto de átomos dinâmicos - por apresentarem um ponto de culminação estático como resultado da realização da situação, ao contrário das atividades. A duratividade deve ser entendida como estritamente operacional, já que qualquer situação, por mais breve que seja, apresenta certa duração.

A proposta de classificação de Bertinetto para o aspecto inerente ao verbo, ou acionalidade, ao considerar três propriedades das classes acionais, consegue minimizar os efeitos da aparente convergência aspectual entre telicidade $\rightarrow$ perfectividade e atelicidade $\rightarrow$ imperfectividade.

\section{SituAÇÃo PASSADA EM CURSO}

Quanto ao valor temporal, IMP e PPROG codificam uma situação passada que apresenta, em maior ou menor grau, sobreposição a uma referência, cuja fórmula é $\mathrm{S}, \mathrm{R}<\mathrm{F}$. Na perspectiva qualitativa do aspecto, IMP e PPROG estabelecem uma relação de inclusão própria do intervalo da referência no intervalo da situação, denominada de imperfectividade, cuja fórmula é S d R. A imperfectividade considerada é a cursiva, ou seja, quanto às fases, a situação é vista como em andamento, em curso. Na perspectiva quantitativa, IMP e PPROG codificam situações que, quanto ao número verbal, são singulares, ou seja, ocorrem uma única vez no intervalo da referência, o que confere o aspecto episódico. As relações entre referência, situação e o momento de fala que caracterizam a equivalência semântica entre IMP e PPROG são dadas no Quadro 5.

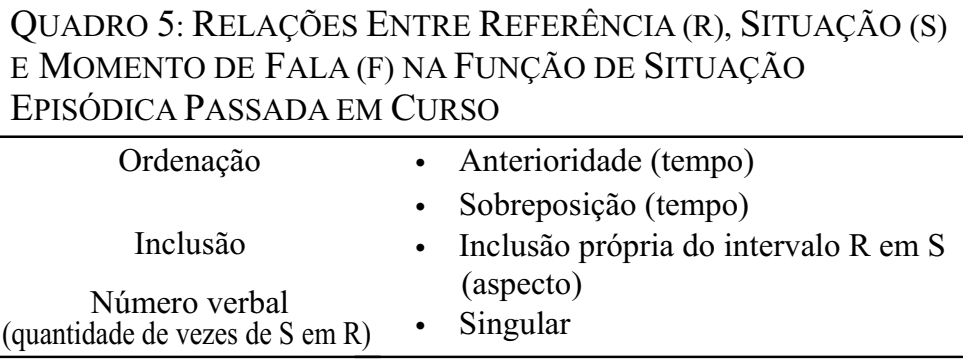


FreitAG, R. M. K. Traços Aspectuais do Pretérito Imperfeito do IndicAtivo E...

Observem-se os casos a seguir.

(9) Eu lembro, eu, durante o período que estudava, hoje no local onde é a Imprensa Oficial do Estado, não na Imprensa Oficial, mas onde tem doze salas de aula do Colégio, foram construídas na época do Governador Esperidião Amin, um prédio de dois pavimentos, ali nós tínhamos a nossa horta da Escola. (SC FLP 21)

Em (9), o verbo em que IMP ocorre, estudava, codifica uma situação episódica passada em curso. Refere-se a uma situação situada anteriormente ao momento da fala, informação que é codificada lexicalmente pelo verbo lembrar (por pressuposição, só há lembrança de um fato passado). O intervalo de referência para a situação não é dado textualmente, mas pode ser inferido com base nas pistas textuais e pelo acionamento das informações compartilhadas; durante o período que eu estudava equivale a um período temporal determinado, algo como entre os anos de 1976 e 1988, por exemplo. A relação entre a situação e a referência quanto à ordenação é de simultaneidade (sobreposição), informação que pode ser inferida e que é reforçada pelo conector temporal durante. Por conta da sobreposição, a relação estabelecida entre a situação e a referência é de inclusão própria da referência na situação e, portanto, a situação é apresentada como em andamento, é imperfectiva cursiva, e também episódica, pois ocorre uma única vez no intervalo da referência temporal. A intercambialidade com PPROG em (9) é possível, como em (10).

(10) Eu lembro, eu, durante o período que estava estudando, hoje no local onde é a Imprensa Oficial do Estado, não na Imprensa Oficial, mas onde tem doze salas de aula do Colégio, foram construídas na época do Governador Esperidião Amin, um prédio de dois pavimentos, ali nós tínhamos a nossa horta da Escola.

O segundo verbo com que IMP ocorre, tínhamos, também pode ser analisado como codificando a função de situação episódica passada em curso. Trata-se de uma situação passada, por conta da ancoragem na referência, que é dada textualmente, a oração subordinada adverbial durante o período que estudava. A relação entre a situação e a referência é também de sobreposição, com inclusão própria do intervalo da referência no intervalo da situação. A situação é imperfectiva, e a existência da horta escolar pode ser considerada como um número verbal singular. A cursividade da situação, porém, fica travada, ou no mínimo, é vista com um considerável esforço de 
aproximação de significação, tanto que a intercambialidade com PPROG não resulta em uma frase usual, espontânea, como em (11).

(11) Eu lembro, eu, durante o período que estava estudando, hoje no local onde é a Imprensa Oficial do Estado, não na Imprensa Oficial, mas onde tem doze salas de aula do Colégio, foram construídas na época do Governador Esperidião Amin, um prédio de dois pavimentos, ali nós estávamos tendo (?) a nossa horta da Escola.

Por que em (10) a intercambialidade é possível e em (11) não? Apesar de as situações codificarem a mesma função, a diferença está nos tipos de verbo. Enquanto estudar é uma atividade, ter, neste caso, é um estado. $O$ traço de aspecto lexical parece ser determinante na determinação da regra variável. Bonomi (1998), no italiano, aponta os efeitos do tipo do verbo na possibilidade de IMP e PPROG funcionarem como equivalentes semânticos, como em (12) e (13).

(12) Quando Miles Davis entrò al Village Vanguard, Bill Evans suonava (IMP) in um trio con Scott La Faro e Paul Motian. Quando Miles Davis entrou (passado, perfectivo) no Village Vanguard, Bill Evans tocava (passado, imperfectivo) em um trio com Scott La Faro e Paul Motian.

(13) Quando Miles Davis entrò al Village Vanguard, Bill Evans stava suonando (PPROG) in um trio con Scott La Faro e Paul Motian.

Quando Miles Davis entrou (passado, perfectivo) no Village Vanguard, Bill Evans estava tocando (passado, imperfectivo) em um trio com Scott La Faro e Paul Motian.

No italiano, IMP e PPROG têm a mesma propriedade semântica quando codificam situação episódica passada em curso ${ }^{9}$ Funcionariam como equivalentes? Bonomi (1998) sugere uma resposta negativa, baseada em uma investigação cuidadosa dos dados. Considerem-se os pares (14), (15) e (16).

(14) a. Ieri alle tre Leo stava correndo (PPROG) nel parco. Ontem às três Leo estava correndo no parque. b. Ieri alle tre Leo correva (IMP) nel parco.

\footnotetext{
Bonomi (1998) não utiliza o mesmo rótulo para situação episódica passada em curso. Entretanto, a função semântica pode ser considerada como a mesma.
} 
FreitAG, R. M. K. Traços Aspectuais do Pretérito Imperfeito do IndicAtivo E...

Ontem às três Leo corria no parque.

(15) a. Ieri alle tre Leo stava dimostrando (PPROG) un teorema. Ontem às três Leo estava demonstrando um teorema.

b. Ieri alle tre Leo dimostrava (IMP) un teorema. Ontem às três Leo demonstrava um teorema.

(16) a. Ieri alle tre Leo stava raggiungendo (PPROG) la vetta Della montagna.

Ontem às três Leo estava alcançando o topo de uma montanha.

b. Ieri alle tre Leo raggiungeva (IMP) la vetta della montagna Ontem às três Leo alcançava o topo de uma montanha.

No par (14), correr é um predicado de atividade e as duas frases são equivalentes, codificando uma situação episódica passada em curso. A idéia é que a atividade estava em curso às $3 \mathrm{~h}$ da tarde. Com verbos de atividade, não parece haver problemas no intercâmbio de IMP e PPROG no português, como ilustram (1) e (2), na seção 1.

O valor de situação episódica passada em curso com PPROG com predicados accomplishment, como demonstrar um teorema, no par (15), com PPROG é perfeitamente natural e espontâneo, mas em (15b), com IMP, é possível, mas não é o mais natural, como é em (16a). Porém, de acordo com Bonomi, ampliando para outros contextos, o valor de situação episódica passada em curso de verbos do tipo accomplishment com IMP é possível, como ilustra o par (17).

(17) a. Lo studente che dimostrava (IMP) un teorema alla lavagna fu interrotto dalla campanella.

o estudante que demonstrava um teorema no quadro foi interrompido pelo sinal.

b. L'auto percorreva (IMP) il suo terzo giro quando il motore si ruppe.

o carro corria (IMP) sua terceira volta quando o motor quebra.

Considerando que a interpretação de situação episódica passada em curso do IMP é aceitável com predicados do tipo accomplishment, como ilustrado no par (17), e assim, a interpretação de (15b), para Bonomi, no par (15), IMP e PPROG também podem ser equivalentes. No português, a ocorrência de IMP em predicados do tipo accomplishment codificando situação episódica passada em curso também é possível, como ilustra (18).

(18) Era dez da noite, a mãe fazia a janta, quando a gente recebeu a notícia que ele se acidentou. (SC FLP 23) 
Já com o par (16), em que IMP e PPROG ocorrem com verbos do tipo achievement, a leitura de situação episódica passada em curso não é possível, e de acordo com Bonomi (1998), as formas não podem ser consideradas equivalentes. Pode-se dizer o mesmo para o português. Considerando o valor de situação episódica passada em curso, Bonomi conclui que:

i) com predicados de atividade, IMP e PPROG são intercambiáveis, sem particular variação de sentido;

ii) com predicados accomplishment, IMP e PPROG podem ser intercambiáveis, dependendo do contexto;

iii) com predicados achievement, IMP e PPROG não são intercambiáveis.

Aparentemente, predicados de estado não são compatíveis com o valor de situação episódica passada em curso; Ilari e Mantoanelli (1983), por exemplo, afirmam que a perífrase estar + gerúndio é compatível apenas com alguns tipos de predicados estativos. Porém, casos de PPROG que ocorrem com verbos de estado podem ser encontrados, como em (19) e (20).

(19) Quando eu comecei a parar pra pensar que tipo de vida que eu estava levando, eu estava achando assim: "Meu Deus, eu sou tão esquisita", eu fiquei pensando comigo assim, né? (SC FLP 03)

(20) A gente, criança e estava imaginando, achava que ele estava lá.

Em (19), estava achando é um predicado de estado e que codifica uma situação episódica passada em curso. O mesmo vale para (20), tanto para o predicado com PPROG como para o predicado com IMP. Atividades, accomplishments e estados têm em comum o traço [+ duratividade], de acordo com a classificação de Bertinetto (2001). Assim, o Quadro 5 precisa ser alterado, para incorporar o traço de natureza lexical, que é determinante para que o valor de situação episódica passada em curso seja assumido por IMP e PPROG.

QUADRO 6: RELAÇÕES ENTRE REFERÊNCIA (R), SITUAÇÃO (S), MOMENTO DE FALA (F) E ASPECTO LEXICAL NA FUNÇÃO DE SITUAÇÃO EPISÓDICA PASSADA EM CURSO

\begin{tabular}{|c|c|}
\hline Ordenação & - Anterioridade (tempo) \\
\hline Inclusão & - Inclusão própria do intervalo $\mathrm{R} \mathrm{em} \mathrm{S}$ \\
\hline Número verbal & - Singular (aspecto) \\
\hline Traço lexical do predicado & $-[+$ durativo $]$ \\
\hline
\end{tabular}


Quando IMP e PPROG apresentarem os traços estabelecidos no Quadro 5, podem ser considerados variantes de uma mesma variável lingüística. Provavelmente é com esta configuração temporal-aspectual que Castilho (2003) e Wachowicz (2003) sugerem que IMP e PPROG podem ser considerados variantes. Ao discutir o estatuto de estar + gerúndio, Castilho afirma que a perífrase não pode ser considerada um tipo de "presente composto", pois indica um estado de coisas que é simultâneo ao momento da fala, o que nem sempre ocorre com o presente do indicativo (cf. seção 1.1). Porém, quando se trata de estarlMP + gerúndio, para Castilho (2003, p. 94) "a correspondência parece quase perfeita". Ele ilustra com (21), que é parafraseável por (22):

(21) meu pai estava morando em Piracicaba, (DID-SP-208: 253)

(22) meu pai morava em Piracicaba.

Ao concluir seu estudo sobre as leituras aspectuais da forma progressiva, Wachowicz (2003, p. 214) pondera que:

\begin{abstract}
se, também, a morfologia flexional do verbo pode funcionar como operador sobre a aspectualidade interna, tal como foi defendido aqui em relação à terminação -ndo do progressivo na determinação do valor durativo, teríamos motivos para levantar a hipótese de que a morfologia -va/-ia, do passado imperfeito, age sob as mesmas condições, visto que podemos afirmar, com base em Godoi (1992b), que a forma do progressivo e a do passado imperfeito estão coocorrendo com a mesma função semântica junto a falantes do português brasileiro.
\end{abstract}

Possivelmente, a mesma função semântica de IMP e PPROG a que se refere Godoi seja situação episódica passada em curso.

Assim, considerando que a função de codificar situação episódica passada em curso seja uma variável lingüística do domínio funcional complexo tempo-aspecto-modalidade (GIVÓN, 1984) ${ }^{10}$, IMP e PPROG podem funcionar como variantes.

10 O domínio funcional é o escopo de atuação de uma dada função desempenhada por uma dada forma em uma dada língua. O termo domínio funcional foi postulado por Givón (1984), e costuma ser evocado freqüentemente em estudos funcionalistas da língua. Hopper (1991, p. 2223), ao tratar de gramaticalização, define o termo como alguma área funcional (tempo, aspecto, modalidade, caso, referência) que freqüentemente se torna gramaticalizado (no sentido de entrar na gramática da língua). 


\title{
RESUMO
}

Com base na análise de Molendijk (2005) do imparfait francês e do passado progressivo do inglês, este estudo enfoca os contextos de equivalência semântica do pretérito imperfeito (IMP) e do passado progressivo (PPROG) no português brasileiro. Assim como no estudo de Molendijk, as formas no português apresentam especificidades, mas em alguns contextos temporais-aspectuais, podem funcionar como variantes. Outros estudos, como Castilho (2003) e Wachowicz (2003), sugerem que IMP e PPROG estão ocorrendo com a mesma função semântica no português brasileiro. Os dados analisados apontam que a função semântica em que IMP e PPRPG apresentam a mesma função semântica é a de situação passada episódica em curso. Essa função toma os pontos de Reichenbach (1947) [tempo de referência (R), tempo de fala (F) e tempo de evento (E)], os traços aspectuais lexicais de Bertinetto (2001), a noção aspecto verbal de Borba Costa (1997), e a relação aspectual de inclusão/exclusão (GODOI, 1992). A função é caracterizada pelos seguintes traços: ordenação: anterioridade e sobreposição (tempo); inclusão do intervalo de $\mathrm{R}$ em $\mathrm{E}$ (aspecto); número verbal: singular; traço lexical [+ duratividade]. As formas podem ser consideradas variantes ou equivalentes semânticos quando apresentam esses traços. Palavras-chave: imperfectivo; passado progressivo; pretérito imperfeito; equivalência semântica.

\begin{abstract}
Based on Molendijk's (2005) analysis of the French imparfait and the past progressive of English, this study focuses the pretérito imperfeito (IMP) and the past progressive (PPROG) in Brazilian Portuguese in context of semantic equivalence. As in Molendijk's study, the forms in Brazilian Portuguese also have differences, but, in some tense-aspect contexts, the forms can be considered as variants. Some studies, Castilho (2003) and Wachowicz (2003) for instance, suggest that IMP and PPROG are occurring with the same semantic function in Brazilian Portuguese. The data point that the semantic function which IMP and PPROG have the same semantic function is the past episodic event in curse. This function take the Reichenbach's points [reference time $(\mathrm{R})$, speech time $(\mathrm{S})$ and event time (E)], the aspectual lexical features (BERTINETTO, 2001), verbal aspect (BORBA COSTA, 1997) and the aspectual relation of inclusion/exclusion (GODOI, 1992). The function is
\end{abstract}


FreitAG, R. M. K. Traços Aspectuais do Pretérito Imperfeito do IndicAtivo E...

characterized by the following features: ordination: anteriority and overlapping (tense); inclusion of $\mathrm{R}$ interval in $\mathrm{E}$ (aspect): verbal number: singular (aspect); lexical feature [+ durativity]. The forms can be considered variants or semantic equivalents when they present these features.

Key-words: imperfective; past progressive; pretérito imperfeito; semantic equivalence.

\section{REFERÊNCIAS}

BERTINETTO, Pier Marco. On a frequent misunderstanding in the temporal-aspectual domain: the 'perfective-telic confusion. In: CECHETTO, Carlo; CHIERCHIA, Gennaro; GIUSTI, Maria Teresa (Eds.). Semantic interfaces: reference, anaphora and aspect. Stanford: CSLI Publications, 2001.

BONOMI, Andrea. Semantical remarks on the progressive reading of the imperfective. Tubingen Workshop on Tense and Aspect, 1998.

BORBA COSTA, Sônia Bastos. O aspecto em português. 2. ed. São Paulo: Contexto, 1997.

CASTILHO, Ataliba. Aspecto verbal no português falado. In: ABAURRE, Maria Bernadete; RODRIGUES, Angela (Orgs.). Gramática do português falado - novos rumos. Campinas: Editora da Unicamp, 2003. v. VIII. p. 83-121.

COMRIE, Bernd. Aspect. Cambridge: Cambridge University Press, 1976.

EMMEL, Ina. "Die kann nun nich', die is'beim treppenputzen": O progressivo no alemão de Pomerode-SC. Tese (Doutorado em Lingüística) - Programa de Pós-graduação em Lingüística da Universidade Federal de Santa Catarina, 2005.

FLEISCHMAN, Suzanne. Irrealis and imperfective. In: BYBEE, Joan; FLEISCHMAN, Suzanne (Eds.). Modality in grammar and discourse. Amsterdam/Philadelphia: John Benjamins Publishing, 1995.

GIVóN, Talmy. Syntax: a functional-typological introduction. Amsterdam/Philadelphia: John Benjamins, 1984.

GODOI, Elena. Aspectos do aspecto. Tese (Doutorado em Lingüística) - Programa de Pósgraduação em Estudos da Linguagem da Universidade Estadual de Campinas, 1992.

HOPPER, Paul. On some principles in the grammaticalization. In: TRAUGOTT, E.; HEINE, B. (Eds.). Approaches to grammaticalization. Philadelphia: John Benjamins Company, 1991. v. 1. p. 17-35.

ILARI, Rodolfo. A expressão do tempo em português. São Paulo: Contexto, 1997.

ILARI, Rodolfo; MANTOANELLI, Ivonne. As formas progressivas do português. In: Caderno de Estudos Lingüísticos. Campinas: IEL, Unicamp, n. 5, p. 27-60,1983.

JOHNSON, Marion. A unified temporal theory of tense and aspect. In: TEDESCHI; ZAENEN (Eds.). Tense and aspect. New York: Academic Press. 1981.

LONGO, Beatriz, CAMPOS, Odete. A auxiliaridade: perífrases de tempo e aspecto no português falado. In: ABAURRE, Maria Bernadete; RODRIGUES, Angela (Orgs.). Gramática do Português falado - novos estudos. Campinas: Editora da Unicamp, 2003. v. VIII. p. 455-475. 
FreitaG, R. M. K. Traços Aspectuais do Pretérito Imperfeito do Indicativo E...

MENDES, Ronald Beline. A gramaticalização de estar + gerúndio no português falado. Dissertação (Mestrado em Lingüística) - Programa de Pós-graduação em Estudos da Linguagem da Universidade Estadual de Campinas, 1999.

MOLENDIJK, Arie. The imparfait in French and the past progressive in English. In: HOLLEBRANDSE, Bart; HOUT, Angeliek van; VET, Co (Eds.). Crosslinguistic views on tense, aspect and modality. Amsterdam: Rodopi, 2005. p. 119-130.

REICHEMBACH, Hans. The tenses of verbs. In: New York: The MacMillan Company, 1947. p. 287-298.

(Ed.). Elements of symbolic logic.

ROTHSTEIN, Susan. Struturing events - A study in the Semantics of Lexical Aspects. Oxford: Blackwell, 2004

VENDLER, Zeno. Verbs and time. In: Lingusitics in philosophy, 1967. p. 97-121.

VERKUYL, Henry. A theory of aspectuality - the interpretation between temporal and atemporal structure. Cambridge: Cambridge University Press, 1993.

WACHOWICZ, Teresa Cristina. As leituras aspectuais da forma do progressivo do português brasileiro. Tese (Doutorado em Lingüística) - Programa de Pós-graduação em Lingüística da Universidade de São Paulo, 2003.

O aspecto do auxiliar. In: ENCONTRO DO GT TEORIA DA GRAMÁTICA DA ANPOLL, 